\title{
Estado de Coisas Inconstitucional: Do Precedente Colombiano ao Leading Case Brasileiro
}

\begin{abstract}
Cristiano Aparecido Quinaia
Mestre em Direito (2017) - Sistema Constitucional de Garantia de Direitos pelo Centro Universitário de Bauru, mantido pela Instituição Toledo de Ensino. Bauru, São Paulo. Advogado. cquinaia@gmail.com
\end{abstract}

\section{Vidal Serrano Nunes Júnior}

Graduado em Direito pela Pontifícia Universidade Católica de São Paulo (1988), obteve os títulos de mestre (1995), doutor (2000) e livre-docente (2008) em Direito pela mesma Universidade. É professor de Direito Constitucional da Faculdade de Direito da PUC-SP e do Programa de Estudos pós-graduados da Instituição Toledo de Ensino de Bauru. Exerce a função de diretor-adjunto da Faculdade de Direito da PUC-SP. É, ainda, procurador de Justiça do Ministério Público do Estado de São Paulo. serranojr@outlook.com

Este texto busca compreender o momento atual do exercício da jurisdição constitucional pela Suprema Corte, iniciando pela análise do histórico das técnicas usadas no controle de constitucionalidade desde a vetusta Suprema Corte dos Estados Unidos, até o uso de modernas técnicas de ativismo e judicialização. Depois, procura entender a declaração de estado de coisas inconstitucional empregada pela Corte Colombiana. Por fim, examina o leading case em tramitação perante o Supremo Tribunal Federal do Brasil, que pretende, ineditamente, aplicar a técnica em casos envolvendo crise do sistema carcerário.

Palavras-chave: Controle. Constitucionalidade. Estado. Colômbia. Ativismo.

STATUS OF THINGS UNCONSTITUTIONAL:

FROM THE PRECEDENT COLOMBIAN TO THE BRAZILIAN LEADING CASE

ABSTRACT

Understand the current moment of constitutional jurisdiction by the Supreme Court. Beginning with the analysis of the history of the techniques used in the control of constitutionality from the old Supreme Court of the United States to the use of modern techniques of activism and judicialization. Then understand the declaration of unconstitutional state of affairs employed by the Colombian Court. Finally, to examine the leading case in the proceedings before the Federal Supreme Court of Brazil that intends to apply the technique in case of crisis involving the prison system.

Keywords: Control. Constitutionality. State. Colombia. Activism. SUMÁRIO

1 Introdução. 2 Linhas Evolutivas da Jurisdição Constitucional. 3 O Precedente da Corte da Colômbia: SU 559/97. 4 O Leading Case no Supremo Tribunal Brasileiro: ADPF 347. 5 Conclusão. 6 Referências. 


\section{Introdução}

Decorridos 800 anos da outorga da Magna Carta pelos barões ao Rei John, discute-se o papel do processo perante a Constituição Federal no exercício da jurisdição constitucional pela Suprema Corte.

Coloca-se em relevo o sensível toque ao sistema de separação de funções sempre que alguma decisão da Suprema Corte adquira o caráter do que se fez habitualmente chamar de técnica de ativismo judicial.

Põe-se, de um lado, a necessidade de se dar efetividade às decisões tomadas no âmbito do controle de constitucionalidade, e, em última análise, de assegurar a supremacia da pronúncia da Suprema Corte como órgão de estatura máxima do Judiciário.

De outro, questiona-se como compreender a atuação jurisdicional ativa com vistas a efetivar políticas públicas, se, por outro ângulo, a administração pública goza de ampla discricionariedade em sua atividade orçamentária.

Nesse compasso, um importante precedente da Corte Colombiana está sendo objeto de análise pelo Supremo Tribunal Federal Brasileiro, visando a copiar a técnica e pôr em prática os preceitos da Constituição Federal de 1988.

As perguntas principais são: Cabe à Suprema Corte o controle de discricionariedade? Pode a Suprema Corte impor mecanismos de monitoramento e direcionamento orçamentário?

Para isso, urge começar os estudos.

\section{Linhas Evolutivas da Jurisdição Constitucional}

Jurisdição, do latim Juris+dictio, significa o poder do Estado ou a função estatal de declarar o direito aplicável ao caso concreto. Extrai-se desse poder o caráter substitutivo de ingerência do Estado-juiz no conflito de interesses.

A jurisdição exerce o escopo social de atuação da vontade da lei, isto é, concretiza aquilo que foi posto na lei. Caso não tenha havido o cumprimento espontâneo do direito, socorre-se, então, ao Poder Judiciário.

De modo geral, a jurisdição pressupõe conflito de interesses, uma lide que é uma disputa qualificada; assim, o juiz interfere nesse conflito estabelecendo a vontade da lei, pacificando a sociedade.

Esse traço não se verifica na jurisdição constitucional, uma vez que, no controle de constitucionalidade exercido pelo Supremo Tribunal Federal, inexiste disputa de interesses e não há caso concreto (BARROSO, 2012, p. 424).

Por meio de Ação Direta por Inconstitucionalidade (ADI) e Ação Declaratória de Constitucionalidade (ADC), o Supremo Tribunal Federal (STF) tem consciência abstratamente de uma controvérsia acerca da interpretação da Constituição. De forma direta e concentrada, a jurisdição constitucional não cuida de interesses particulares e conflitos individuais, mas, sim, aspira restabelecer a ordem fundamental.Toda jurisdição é definitiva no sentido de que esgota a possibilidade de discussão posterior do assunto. Uma vez existindo uma sentença ou acórdão transitado em julgado, forma-se, em definitivo, aquele entendimento.A doutrina pro- 


\section{Democracia}

cessualista de Dinamarco e Grinover (2006, p. 84) e Dantas (2013, p. 183), fala em um ramo de Direito Processual Constitucional que abrange os princípios que regulam o devido processo legal. De outro lado, existe o Direito Constitucional Processual, que disciplina os remédios constitucionais, a tutela das liberdades e o controle de constitucionalidade.

A jurisdição constitucional ascende, sobretudo no período entre as duas grandes guerras mundiais, como uma resposta à soberania do Monarca ou do Parlamento aos desmandes praticados ao longo da Idade Média.

Assim, o positivismo (BARROSO, 2012, p. 424), a partir da década de 50 do século 20, caiu em desuso, ou, pelo menos, entrou em crise, por conta dos abusos nazistas e fascistas perpetrados em nome do cumprimento da lei.

Ascenderam-se técnicas de aplicação do direito com mecanismos que buscavam a concretude da decisão judicial. O Poder Judiciário sairia das raias de mera bouche de loi para se tornar guardião dos direitos assegurados pela Constituição.

A Suprema Corte dos Estados Unidos já se havia destacado em razão da decisão sobre a judicial review, proferida pelo chief justice Marshall, que fixou as vigas mestras da supremacia do direito sobre a vontade política.

Nessa nova etapa, o Poder Judiciário deixava de ser mero espectador que teria de aguardar a aprovação de uma lei para poder instituir o direito, passando, então, a aferir a compatibilidade da lei com a vontade suprema.

O Judiciário tornava-se, então, protagonista; a última instância de refúgio do povo quando os demais poderes políticos não dispunham de ferramentas para tornar prático o seu direito.

Além da apuração da observância do procedimento para aprovação da lei, o Judiciário passa a aferir a razoabilidade e a compatibilidade na técnica que seria chamada de substantive due process, isto é, não apenas o aspecto formal e adjetivo, mas o caráter substancial do conteúdo.

Com essa tendência, os juízes passam a fiscalizar a disposição dos direitos e sua compatibilidade com a vontade política disposta na Constituição Federal, que não pode ser relegada.

Não bastava, todavia, que os políticos seguissem as regras formais para aprovação da lei, mas que rendessem deferência às competências fixadas pela Constituição dos Estados Unidos.

No que se refere aos juízes da Suprema Corte dos Estados Unidos, esse movimento foi seguido nas gerações subsequentes ao caso Marshall, com vindouras e inéditas decisões sobre o controle de constitucionalidade das leis.O termo atualmente conhecido como ativismo, em verdade, "é uma expressão cunhada nos Estados Unidos e que foi empregada, sobretudo, como rótulo para qualificar a atuação da Suprema Corte durante os anos em que foi presidida por Earl Warren, entre 1954 e 1969" (BARROSO, 2012, p. 427).

Earl Warren presidiu a Suprema Corte por mais de uma década e, sob sua condução, foi responsável por julgamentos épicos que despontaram a interpretação de garantias fundamentais inéditas, como a igualdade e a assistência judiciária integral. 
Entre os casos célebres, destaca-se Brown v. Board of Education, do ano de 1954, no qual se discutia a segregação racial e o contexto da separação que se fazia entre as escolas de brancos e de negros nos Estados Unidos.

Brancos e negros não sentavam ao lado nas salas de aula, nem apanhavam o mesmo ônibus escolar, sendo severo o apartheid que se fazia presente na realidade das crianças e adolescentes estadunidenses.

O caso, então, chegou à Suprema Corte dos Estados Unidos, que deveria analisar, sob o prisma do pacto federativo, a competência dos Estados para disporem sobre o ensino, inclusive sobre a segregação.

Earl, com lapidar sapiência, tangenciou a questão sobre raça e racismo, pois enfrentaria forte pressão interna da corte e externa de grande parte da população, que era altamente racista.

O Chief of Justice partiu do pressuposto do princípio da igualdade, no sentido de que o mesmo ônibus no qual o aluno branco pode ser transportador também deve recepcionar o aluno negro, pois ambos são cidadãos estadunidenses.

Logo, se os Estados Unidos da América comprometeu-se em prestar a educação, devia fazê-lo em pé de igualdade com todas as crianças e adolescentes, sem qualquer discriminação quanto a aspectos étnicos.

A ligação do cidadão com o Estado - com vínculo de súdito - fazia-o credor de igual direito conferido a qualquer outro indivíduo, razão pela qual privações implicavam pretensão de obrigação pelo Poder Público.

A Suprema Corte, então, declarou ser incompatível com o pacto constitucional ofertar, de forma diversa, o mesmo serviço público de educação a alunos brancos e negros.Outro célebre caso decidido nesse período é Gideon v. Wainwright 372 US 335, do ano de 1963, quando a corte enfrentou o dilema a respeito do direito de defesa do acusado criminalmente.

Clarence Gideon foi acusado de prática delituosa perante o Tribunal da Flórida, e no dia da sessão de julgamento compareceu sozinho, desacompanhado de advogado.

Requereu, então, ao juiz que presidia o feito, que lhe fosse nomeado um advogado público, o que foi indeferido, sob o argumento de que apenas acusados pobres e com crime de pena capital faziam jus à assistência judiciária.

Gideon defendeu-se durante todo o processo sozinho, fazendo seus arrazoados, porém foi condenado. Recorreu, nessa situação, à Corte do Estado da Flórida, sendo negado seu pedido. Ingressou, então, com pedido na Suprema Corte dos Estados Unidos, com base na 6a Emenda, que assegura:

Em todos os processos criminais, o acusado terá direito a um julgamento rápido e público, por um júri imparcial do Estado e distrito onde o crime houver sido cometido, distrito esse que será previamente estabelecido por lei, e de ser informado sobre a natureza e a causa da acusação; de ser acareado com as testemunhas de acusação; de fazer comparecer por meios legais testemunhas da defesa, e de ser defendido por um advogado (SUPREMA..., 2017a). 


\section{Democracia}

Humanos

A Suprema Corte definiria se a interpretação a ser conferida a esta emenda equivale a sustentar a obrigação de os Estados prestarem assistência integral nas acusações perante seus Tribunais de Justiça.

Na decisão, a Suprema Corte concedeu o writ of certiorari, ou seja, reconheceu o cerceamento de direito de Gideon e pronunciou no mérito, reconhecendo que o Tribunal deveria reverter a decisão, recomeçando a instrução do caso com a concessão de advogado de defesa a Gideon.

Esse precedente histórico é de suma importância para compreender o alcance da cláusula do devido processo legal, sendo certo que hoje, no Brasil, o Supremo Tribunal Federal já solidificou entendimento de que a assistência judiciária deve ser amplamente interpretada, de forma a assegurar ao cidadão, seja ele brasileiro ou estrangeiro em trânsito pelo território nacional, toda assessoria jurídica em qualquer etapa do procedimento, com a mais ampla defesa, os recursos a ela inerentes, os meios probatórios, tais como a perícia, a serem custeados também pela Administração da Justiça, consoante é possível extrair do aresto a seguir colacionado, sob a lavra do eminente Ministro Carlos Velloso:

Ementa: - CONSTITUCIONAL. ACESSO À JUSTIÇA. ASSISTÊNCIA JUDICIÁRIA. Lei 1.060, de 1950. C.F., art. 5ㅇ, LXXIV. I. - A garantia do art. 50, LXXIV - assistência jurídica integral e gratuita aos que comprovarem insuficiência de recursos - não revogou a de assistência judiciária gratuita da Lei 1.060, de 1950, aos necessitados, certo que, para obtenção desta, basta a declaração, feita pelo próprio interessado, de que a sua situação econômica não permite vir a Juízo sem prejuízo da sua manutenção ou de sua família. Essa norma infraconstitucional põe-se, ademais, dentro no espírito da Constituição, que deseja que seja facilitado o acesso de todos à Justiça (C.F., art. 5o, XXXV). II. - R.E. não conhecido. RE 205746 RS. Segunda Turma. CARLOS VELLOSO.

Outro importante precedente da Corte Warren é o caso Miranda v. Arizona, no qual se abordou os direitos do preso quanto a interrogatório, depoimentos, acusação e nomeação de advogado.

Miranda foi preso em sua casa, identificado por uma testemunha, conduzido à Delegacia onde, após duas horas de interrogatório, obteve-se sua confissão escrita e assinada. Com base nessa prova oral colhida de seu depoimento, Miranda foi levado a júri e veio a ser considerado culpado pela prática de estupro e sequestro, recebendo pena de 20 anos de prisão.

A Suprema Corte conferiu interpretação a 5a Emenda, que assegura o devido processo legal não apenas no âmbito do processo judicial, mas a qualquer procedimento criminal no qual a pessoa seja investigada e acusada.

A decisão considerou supremo o direito de obter garantias e salvaguardas para que a pessoa não se veja obrigada a incriminar-se para se livrar de tortura ou qualquer meio infamante.

Assim, o acusado deve ser avisado sobre seu direito ao silêncio, ao advogado, bem como de que qualquer declaração poderá ser usada contra si perante o julgamento no Tribunal. 
Esse padrão decisório de ativismo, embora usualmente empregado para designar qualquer decisão da jurisdição constitucional moderna, em verdade é empregado esporadicamente pelo Supremo Tribunal Federal Brasileiro.

Por diversas ocasiões a Suprema Corte do Brasil destacou-se na defesa dos direitos das minorias, grupos vulneráveis e excluídos da política elitizada.

O precedente mais significativo, sem dúvida, é a Ação Direta de Inconstitucionalidade 4277 e Arguição de Descumprimento de Preceito Fundamental 132,quando se discutiu a possibilidade de reconhecimento de união estável homoafetiva, entre pessoas do mesmo sexo.

Naquele precedente, o relator ministro Carlos Ayres Britto votou no sentido de entender que, inexistindo vedação expressa pela Constituição e considerando os predicados da igualdade e da dignidade da pessoa humana, o disposto na legislação ordinária não poderia conduzir à restrição da união estável.

Sustentou o relator que "o sexo das pessoas, salvo disposição contrária, não se presta para desigualação jurídica", até porque o artigo 5ำ, caput, é expresso em vedar essa interpretação.

Nesse caso, observa-se que a Corte não se limitou em dar a interpretação, mas foi além para permitir o exercício de um direito civil que não contava com previsão legal. Essa constitui a típica técnica de ativismo.

De outro lado, constata-se outra tendência do pós-guerra e consequência da globalização - a judicialização -, que "significa que questões relevantes do ponto de vista político, social ou moral estão sendo decididas, em caráter final, pelo Poder Judiciário" (BARROSO, 2012, p. 425), ou melhor, pela Suprema Corte.

Há dois destaques nesse tema. O primeiro no sentido de que a Suprema Corte se tornou salvaguarda também para o exercício das prerrogativas parlamentares, não sendo difícil encontrar casos nos quais tenha de se manifestar sobre a obediência da proposta de lei ao devido processo legislativo.

De outro lado, o presidencialismo de coalização tem implicado a sobrepujança de minorias parlamentares, que se socorrem do Poder Judiciário para exercer seu direito de veto e de voto.

No constitucionalismo brasileiro a nota marcante é a necessidade de constante "negociação em torno de diretivas programáticas mínimas" (ABRANCHES, 1988, p. 27), quer dizer, a aprovação de medidas e textos legais sempre requer a composição, o acordo, a troca de favores.

Em outro aspecto, algumas decisões políticas podem ser infames por prejudicar interesses de setores lobistas para campanha eleitoral, razão pela qual ter uma decisão da Suprema Corte que obrigue o titular de mandato legislativo a atender ao reclamo orçamentário em detrimento de interesse especial, pode ser menos ofensivo à situação do que à oposição.

\section{O Precedente da Corte da Colômbia: SU 559/97}

Dentro dessa linha de atuação intensa das Supremas Cortes no âmbito da jurisdição constitucional, há um importante precedente de um tribunal sul-americano que, em que pese decorridas duas décadas, inspira reflexão até os dias atuais. 


\section{Humanos e \\ Democracia}

Em 1997 a Suprema Corte da Colômbia foi convocada a manifestar-se em um caso envolvendo o cerceamento de direitos sociais de professores da rede pública de ensino, cujas necessidades foram relegadas pela administração pública.

A situação narrada dava conta de professores de rede de ensino básico que sofriam o desconto para contribuição ao fundo social, porém não estavam afiliados a nenhuma entidade de gestão desses direitos sociais.

Essa falha da administração causava muitos transtornos aos docentes, prejudicando, indiretamente, a qualidade do serviço de educação que a todos era assegurado pela Constituição do Estado como direito social básico.

Uma questão interessante que foi enfrentada pela Corte Colombiana diz respeito à compreensão da discricionariedade da administração executiva; ela não engloba a faculdade de decidir sobre a eficácia ou ineficácia de direitos sociais. Ou seja,

há discricionariedade desde que não envolva tarefas fundamentais a serem cumpridas pelo Estado, de forma que não seja hábil em causar prejuízos a direitos da população, sobretudo aos estratos pobres que precisam de educação pública de qualidade.

Logo, o argumento da inexistência de recursos para criação do fundo ou caixa de amparo aos professores não era hábil de justificar-se pela discricionariedade da administração pública, e, de tal sorte, restou superado.

De forma pioneira, a Corte Colombiana reconheceu naquele caso a constatação de um estado de cosas contrario a la Constitución Politica; técnica de julgamento que ficou conhecida como o estado de coisas inconstitucional.

Naquela situação, abespinhou-se a Suprema Corte pelo fato de que a situação da rede de ensino público municipal chegou ao Tribunal de Estado e ao conhecimento da administração estadual, que nada fez.

Por fim, ascendeu à Suprema Corte e, até então, nem a Administração Federal havia se comovido com a situação dos alunos e dos docentes, razão pela qual reconheceu uma situação de total descumprimento daquele direito social por todas as esferas do poder.

Como destacado, naquele caso havia previsão de estatura constitucional e infranormativa no sentido de reconhecer o direito que estava sendo perseguido, não se invocando ativismo ou inovação jurisdicional. Consoante a fundamentação,

La disposición del Decreto 196 de 1995 es clara en el sentido de determinar que todos los educadores de los entes departamentales, distritales y municipales deben ser afiliados al Fondo Nacional de Prestaciones Sociales del Magisterio, obligación que no puede ser soslayada a través de la instauración en los municipios de mecanismos informales de seguridad social.

O que ocorreu foi que, a despeito da ordem legal, a administração quedou-se inerte, pondo em xeque o importante serviço de educação pública, com prejuízo à população e aos profissionais envolvidos na missão de educar.

Pronunciado o estado de coisas inconstitucional, a Suprema Corte Colombiana passou, então, a estudar um mecanismo processual para tornar efetiva sua decisão, que pudesse praticamente concretizar o direito sem, contudo, implicar ofensa à separação das funções. 
A primeira providência a ser adotada era a notificação ao órgão administrativo, para que não protraia recalcitrante no cumprimento da disposição constitucional, cessando, desde logo, a ofensa ao cumprimento das normas fundamentais.

A Corte Colombiana, porém, foi além, fixando o prazo de um ano para que a administração pública responsável efetuasse o cumprimento do direito de afiliação dos professores, com a obrigação de prestação de contas.

Muito se discute a respeito da consequência jurisdicional de um pronunciamento da Suprema Corte que reconheça o estado de coisas inconstitucional, ou seja, alguma providência haveria de ser tomada, como fez a Corte Colombiana, a fim de que ali seja cessada a ofensa.

Consoante se sabe, a Suprema Corte é a instância última e máxima do Poder Judiciário, de tal sorte que, depois dela, a esperança do cidadão há de ser apagada e suas decisões devem possuir o máximo de efetividade.

Afinal, o Direito Constitucional liga o universo jurídico ao plano decisório do político, daí decorrendo a responsabilidade do juiz constitucional na fiscalização e condução de sua efetividade (ROYO, 1995, p. 52).

\section{Leading Case no Supremo Tribunal Brasileiro: ADPF 347}

Assim como as técnicas de jurisdição constitucional expandiram-se da Suprema Corte dos Estados Unidos, também este mecanismo da Corte Colombiana tem influenciado sobremaneira o exercício da competência do Supremo Tribunal Federal do Brasil.

Há algum tempo é denunciada a situação precária dos presídios pelo país, desde a questão estrutural da superlotação até o problema orgânico da laborterapia, educação, reinserção, como óbices à eficácia do sistema como um todo.

Adotando como base relatórios do próprio Conselho Nacional de Justiça (CNJ) e de outras instituições, chegou ao Supremo Tribunal Federal uma Arguição de Descumprimento de Preceito Federal 347 (ADPF), questionando o sistema carcerário brasileiro e buscando a declaração de um estado de coisas inconstitucional.

A ação foi entregue ao ministro Marco Aurélio para apreciação de medida cautelar, cujo julgamento plenário seguiu quase que totalmente o voto proferido pelo relator. Restringindo algumas medidas concretas para o julgamento de mérito, contudo, publicou-se a seguinte ementa:

FUNDO PENITENCIÁRIO NACIONAL - VERBAS - CONTINGENCIAMENTO. Ante a situação precária das penitenciárias, o interesse público direciona à liberação das verbas do Fundo Penitenciário Nacional. AUDIÊNCIA DE CUSTÓDIA - OBSERVÂNCIA OBRIGATÓRIA. Estão obrigados juízes e tribunais, observados os artigos 9.3 do Pacto dos Direitos Civis e Políticos e 7.5 da Convenção Interamericana de Direitos Humanos, a realizarem, em até noventa dias, audiências de custódia, viabilizando o comparecimento do preso perante a autoridade judiciária no prazo máximo de 24 horas, contado do momento da prisão. 


\section{Democracia}

De forma interessante, no julgamento foi levantado o cenário épico do Inferno, narrado por Dante de Alighieri, épica obra literária na qual se descreve sua passagem pelo purgatório, a travessia na canoa de Carontes, até o paço e limbo no qual sofrem os criminosos de acordo com a natureza do crime capital que tenha sido por ele praticado, em um cenário infernal de dor, angústia, consoante descrição surreal levada a cabo pelo eminente escritor italiano:

Eis a estância, que eu disse, às dores feita,

Onde hás de ver atormentada gente,

Que da razão à perda está sujeita.

Por esse ar sem estrelas irrompia

Soar de pranto, de ais, de altos gemidos:

Também meu pranto, de os ouvir, corria (2003, p. 32).

Dessa forma ficou caracterizado o sistema prisional brasileiro, em condições desumanas, cujo suplício a que se submetem os condenados faz-lhe aumentar seu ódio social e impossibilitar a tarefa de ressocialização, conforme elucidou o relator:

Conforme esclarece, a técnica da declaração do "estado de coisas inconstitucional" permite ao juiz constitucional impor aos Poderes Públicos a tomada de ações urgentes e necessárias ao afastamento das violações massivas de direitos fundamentais, assim como supervisionar a efetiva implementação.

De tal sorte, a decisão final da Suprema Corte foi no sentido não apenas de declarar presente o estado de coisas inconstitucional, senão também, desde logo, fixar o prazo de 90 dias para que o Ministério da Justiça tornasse possível a realização de audiência de custódia, visando à apresentação do caso ao juiz de direito que decidirá pela remessa do acusado à enxovia.

Cabe registrar que o julgamento ainda não foi pautado no mérito para o Plenário da Suprema Corte, no entanto, pelo voto do relator ministro Marco Aurélio, a decisão não se resume em declarar o estado de coisas, mas, também a determinar mecanismos de fiscalização para o cumprimento da ordem:

Aponta caber ao Supremo, ou quem lhe faça as vezes, o monitoramento da fase de implementação, devidamente auxiliado por entidades dotadas do indispensável conhecimento, inclusive com a participação deliberativa da sociedade civil. Dessa forma, o Tribunal interviria sem abrir mão "do potencial institucional dos outros poderes".

Entende-se, nesses casos, que a Suprema Corte não age ativamente criando política pública, mas como "coordenador institucional" (GARAVITO, 2010, p. 39), realinhando as diretivas orçamentárias a partir do texto constitucional.

\section{Conclusão}

Do que foi dito constata-se a redemocratização do orçamento público, que sai das raias privativas do chefe do Executivo e passa a ser objeto de análise e revisão pela Suprema Corte, com vistas a possibilitar o cumprimento do programa constitucional. 
Em países como o Brasil, que enfrenta o dilema do presidencialismo de coalização que carrega a direção dos partidos políticos junto ao Congresso Nacional, a participação e a direção do Supremo Tribunal Federal faz-se de rigor, considerando que o princípio que rege o pacto federativo é a independência, porém com harmonia entre os poderes.

Considerando que alguma das funções essenciais do poder estatal seja malversada pela Administração Executiva, caberá, sim, ao Supremo Tribunal Federal, fiscalizar o distanciamento da finalidade dos programas constitucionais.

\section{Referências}

ABRANCHES, Sérgio. Presidencialismo de coalização: o dilema institucional brasileiro. Revista de Ciências Sociais, Rio de Janeiro, v. 31, n. 1, p. 5-14, 1988.

ALIGHIERI, Dante de. Divina comédia. São Paulo: Editora Ebooks Brasil, 2003.

BARROSO, Luís Roberto. O controle de constitucionalidade no direito brasileiro. São Paulo: Saraiva, 2012.

DANTAS, Ivo. Direito processual constitucional e direito constitucional processual: um debate em aberto. Revista Acadêmica, Ufpe, vol. 85, n. 2, 2013.

DINAMARCO, Cândido Rangel; GRINOVER, Ada Pelegrine. Teoria geral do processo. São Paulo: Malheiros, 2006.

GARAVITO, César Rodríguez; FRANCO, Diana Rodríguez. Cortes y Cambio Social. Cómo la Corte Constitucional transformó el desplazamiento forzado en Colombia. Bogotá: Dejusticia, 2010.

ROYO, J. Perez. Curso de Derecho Constitucional. Madrid: Marcial Pons, 1995.

SUPREMA CORTE DOS ESTADOS UNIDOS DA AMÉRICA. Disponível em: <http://www.uscourts.gov/educational-resources/educational-activities/facts-and-case-summary-gideon-v-wainwright>. Acesso em: 25 abr. 2017 a.

Disponível em: <http://www.uscourts.gov/educational-resources/educational-activities/facts-and-case-summary-miranda-v-arizona>. Acesso em: 25 abr. 2017b. 